\title{
Transformando 'Verdades Abstratas' em 'Verdades Concretas': Uma Análise Sobre a Metodologia Econômica de John Stuart Mill
}

Laura Valladão de Mattos
Professora da Pontifícia Universidade Católica de São Paulo - PUC-SP

\section{RESUMO}

Visa-se explicar como se daria, segundo Mill, a transformação das 'verdades abstratas' da ciência da economia política - engendradas a partir da utilização da abstração "homem econômico' - em 'verdades concretas' passíveis de serem utilizadas para previsão dos eventos e como base para a formulação de política econômica. Argumenta-se que seria necessário não só 'humanizar' o 'homem econômico', levando em conta motivações humanas que são propositadamente excluídas pela ciência da economia política, como também considerar peculiaridades institucionais de cada caso. Conclui-se que, apesar do sucesso de Mill em transformar verdades abstratas em concretas, os seus escritos metodológicos são por demais vagos e insuficientes para nos servir de guia nesta importante questão.

\section{PALAVRAS-CHAVE}

John Stuart Mill, método dedutivo, "homem econômico", ciência da economia política, etologia, abstração, economia aplicada

\section{ABSTRACT}

We aim at explaining Mill's view on the transformation of the 'abstract truths' of the science of political economy - obtained by using the 'economic man' abstraction - in 'concrete truths', which could be used both to predict events and as support for policy decisions. We argue that it would not only be necessary to 'humanize' the 'economic man' by taking in account several human motivations that are not considered by the science of political economy, but also to take in account the institutional peculiarities of each case. We conclude that despite Mill's success on his attempts to transform 'abstract' in 'concrete' truths, his methodological advices are too vague and insufficient to guide us in this important issue.

KEY WORDS

John Stuart Mill, deductive method, "economic man", science of political economy, ethology, abstraction, applied economics

JEL Classification

$B / 20$ 


\section{INTRODUÇÃO}

John Stuart Mill elaborou o que foi talvez a primeira defesa metodológica do homem econômico. Com base nesta abstração, ele atribuiu à ciência da economia política e às suas conclusões um caráter eminentemente abstrato. Por outro lado, Mill tinha um projeto enquanto reformador social e certamente desejava ver essa importante ciência a serviço do melhoramento da sociedade. Explicitar a forma pela qual se poderia transformar o conhecimento abstrato que decorria das reflexões científicas em conhecimento passível de ser utilizado na prática aparece, assim, como uma questão metodológica importante a ser resolvida.

Analisando, entretanto, os seus principais escritos metodológicos muitas dúvidas restam sobre como Mill pretendia preencher essa lacuna existente entre o conhecimento abstrato fornecido pela ciência da economia política e o conhecimento concreto necessário para tornar possível explicar (e manipular) os acontecimentos concretos nessa esfera da vida social. ${ }^{1}$

Assim, esse artigo tem como objetivo tentar avançar no entendimento de como se daria, para Mill, a ponte entre a ciência e a aplicação dos seus princípios à prática. Para tanto, o artigo será organizado da seguinte forma:

Num primeiro momento analisarei a definição e o método da ciência da economia política enfatizando o status abstrato de suas conclusões. Num segundo momento, a investigação volta-se para a aplicação da ciência. Nessa parte serão discutidas as contribuições da etologia política (ciência da formação do caráter) e de outros tipos de conhecimento na empreitada de

1 Muitos artigos já foram escritos sobre a metodologia de Mill. Podemos citar, entre outros, BLAUG (1993), COLLINI (1983), DE MARCHI (1970, 1974, 1988 e 2000), EDGEWORTH (1896), FEUER (1976), HAUSMAN (1981), HIRSCH (1982), HOLLANDER (1985), LEARY (1982), LEWISOHN (1972), MARSHALL (1982), MATTOS (1999a), MOTTA (1988), PERSKY (1995), POPPER (1968), PRADO (1991), RYAN (1990), WHITAKER (1975). No entanto, recentemente foi aberto um novo 'round' na literatura especializada com os artigos de HOLLANDER \& PEART (1999 e 2000) e HIRSCH (2000), reavivando o interesse no tema e introduzindo novas idéias ao debate. O objetivo deste artigo é abordar alguns pontos que ainda me parecem pouco explorados à luz dessa literatura mais recente sobre o tema. Em relação ao debate recente, eu tendo a concordar com a posição de Hirsch e estarei utilizando fartamente a sua interpretação no artigo que segue. 
transformar verdades abstratas em verdades concretas. A seguir, discutir-se-á o papel que a verificação desempenha nesse processo. Por fim, ao final do artigo, serão feitas algumas considerações sobre o sucesso (ou não) deste projeto de construir uma ponte entre a ciência e o real.

\section{AS VERDADES ABSTRATAS DA CIÊNCIA DA ECONOMIA POLÍTICA ${ }^{2}$}

Mill apresenta a ciência da economia política como sendo uma ciência que lida apenas com uma fração das motivações humanas. Esta ciência preocupase com o homem "(...) somente enquanto ser que deseja possuir riqueza, e que é capaz de avaliar a eficácia comparativa dos meios para obter aquele fim. Prediz unicamente aqueles fenômenos do estado social que ocorrem em conseqüência da busca de riqueza. Faz total abstração de toda outra paixão ou motivo humano, exceto aqueles que podem ser tidos principios perpetuamente antagonistas ao desejo de riqueza, notadamente a aversão ao trabalbo e o desejo de satisfação presente de indulgências dispendiosas.” (MILL, Ensaio, p. 300, CW IV, p. 321).3

Como mencionado acima, essa foi talvez a primeira versão da espécie homem econômico - que, modificada, reina até hoje no estudo da economia. ${ }^{4}$ Apesar de Mill nunca ter utilizado diretamente o termo, foi como reação ao seu trabalho que a denominação homem econômico entrou no voca-

2 Para o estudo da definição e do método da economia política vou centrar-me no artigo "Da definição da economia política e o do método de investigação próprio a ela" (doravante Ensaio), sem um estudo mais aprofundado do Sistema de Lógica (doravante Lógica). A justificativa para tanto é que no intervalo entre a elaboração do Ensaio (1830/1) e a publicação da Lógica em 1843, a sua visão de método da economia política pouco se alterou. Tanto que ele reproduz literalmente grandes trechos do Ensaio quando se refere a essa ciência na Lógica.

3 Estou utilizando a tradução do Ensaio feita por Pablo Mariconda nos Pensadores, mas achei interessante colocar também a referência das citações no $C W$. A tradução de Mariconda é, em geral, boa, no entanto, no caso da passagem citada ela não ficou clara. Um dos pareceristas anônimos da revista chamou a atenção para esse fato e sugeriu uma tradução alternativa, que me parece superior, na qual se leria: "o desejo de satisfação imediata de prazeres custosos" em lugar de "o desejo de satisfação presente de indulgências dispendiosas.” Além das três motivações já citadas, Mill abre a possibilidade de, para fins didáticos, incorporar no âmbito da ciência da economia política a questão populacional. Por conta disso, Persky afirma: "(...) O homem econômico de Mill tem quatro interesses distintos: acumulação, lazer, luxo e procriação (...).” (PERSKY, 1995, p. 223).

4 Para um estudo das transformações que o 'homem econômico' sofreu ao longo da história da economia, ver FONSECA (1990). 
bulário dos economistas e o seu nome ficou definitivamente associado a essa abstração. ${ }^{5}$

O que levou Mill a essa definição de ciência da economia política foi o entendimento de que seria impossível, a partir da realidade complexa, inferir as relações causais que estariam a ela subjacentes. A utilização do método a posteriori seria inviável pelo fato de os fenômenos sociais serem resultado de uma concorrência das causas, sendo impossível empreender, neste campo de fenômenos, experimentos controlados. ${ }^{6}$

Com efeito, um dos objetivos de Mill ao escrever o Ensaio foi o de mostrar que o método a posteriori (ou da experiência específica), geralmente adotado pelos 'homens práticos', era inadequado no campo da economia. (HIRSCH, 2000, p. 352). Generalizações empíricas teriam, como veremos adiante, um papel a cumprir no momento de aplicação dos princípios científicos. No entanto, esse método seria, para Mill, totalmente inadequado como forma de chegar aos princípios da ciência, e boa parte do argumento de Mill visava mostrar que esse procedimento era incorreto e deveria ser evitado para não se cair num empirismo ingênuo.?

5 Segundo Persky, num primeiro momento o termo foi usado de forma pejorativa pelos adeptos da Escola Histórica que criticavam fortemente a economia abstrata e dedutiva praticada por Mill e pelos demais ricardianos. Ao criticar a economia política milliana, John Ingram teria utilizado o termo homem econômico pela primeira vez ao dizer que Mill "não lidou com homens reais e sim com homens imaginários - 'homens econômicos' (...) concebidos apenas como animais acumuladores de dinheiro (money-making animals)." (INGRAM, A history of political economy, apud PERSKY, 1995, p. 222). Marshall, já no começo do século 20, mostra como o nome de Mill ficou atrelado ao homem econômico: "(...) a hostilidade que empresários e homens de negócios revelam agora em relação à economia, não é devido a nada realmente feito pelos economistas, mas devido a coisas que os lógicos, $\mathrm{em}$ especial Mill, disseram que eles fizeram e que foi ecoado e re-ecoado milhões de vezes.” (MARSHALL, carta para Neville Keynes, apud, WHITAKER, 1975, p. 1045). Apesar disso, Marshall é um dos autores a argumentar que em seus Princípios Mill em momento algum seguiu à risca o que apregoou em termos metodológicos.

6 De Marchi descreve bem o problema: “(...) o fenômeno econômico, on os efeitos observados, resultam de causas combinadas e o conbecimento do resultado é em geral insuficiente para inferir de volta as causas envolvidas. Se for para fazer sentido de - ou para atribuir uma causa ou causas a - esse tipo de observação, nós precisamos conbecer quais são as causas e qual é ação precisa delas antes de observar qualquer efeito conjunto." (DE MARCHI, 1988, p. 149/50).

7 Sobre isso Hirsch aponta "(...) o seu ponto é que, de qualquer forma, estamos numa situação melhor aplicando a ciência abstrata até onde ela vai, do que confiando em meras correlaçôes como faz o homem prático.” (HIRSCH, 1992, p. 849). 
Assim, apesar de ter ficado conhecido por seus cânones da indução, Mill conclui que nas ciências sociais (economia política aí incluída) o método indutivo não seria adequado. ${ }^{8}$

Mas isso não significava, para Mill, a inviabilidade do empreendimento científico neste campo de fenômenos. Por uma feliz coincidência, os homens teriam, na esfera dos fenômenos sociais, acesso direto às causas. As principais causas seriam, no seu entender, as motivações humanas, e estas os homens conheciam por meio da introspecção:

"Essas causas são as leis da natureza humana e as circunstân-
cias capazes de excitar a vontade humana à ação. Os desejos
do homem e a natureza da conduta para a qual eles o incitam
estão ao alcance de nossa observação. Podemos observar também
quais são os objetos que excitam aqueles desejos. Qualquer um
pode fundamentalmente colher os materiais deste conhecimento
dentro de si próprio, com a consideração racional das diferenças,
as quais a experiência lhe revela a existência entre ele próprio
e as outras pessoas (...)." (MILL, Ensaio, p. 307, CW IV,
p. 329).

Assim, no campo das ciências morais, a forma de abordar fenômenos - resultados da ação conjunta de várias causas - seria considerar o resultado da operação de cada causa (conhecida por introspecção) agindo separadamente para depois estimar o seu resultado conjunto. Nas palavras de Mill:

$$
\begin{aligned}
& \text { "(...) De modo a julgar como agirá sob a variedade de desejos } \\
& \text { e aversões que estão operando conjuntamente sobre ele, deve- }
\end{aligned}
$$

8 Mill desenvolve a lógica indutiva nos primeiros livros da Lógica, nos quais ele trata das ciências naturais. Existiriam várias formas de se chegar às relações causais a partir da experiência, e os principais cânones da indução seriam: o método do acordo; o método da diferença; o método dos resíduos; e o método das variações concomitantes. (BLAUG, 1993, p. 109, rodapé 10). E nenhum destes métodos seria passível de ser utilizado no âmbito das ciências morais. Ao comentar a Lógica, Blaug afirma: “(...) após devotar quase todo o livro à defesa dos métodos indutivos na ciência e na matemática, Mill aborda na parte final a metodologia do que denominou 'ciências morais' (significando ciências sociais), onde surpreendentemente aceita que os métodos indutivos sejam considerados imuteis (...).” (BLAUG, 1993, p. 108). 
mos saber como ele agiria sob a influência exclusiva de cada uma em particular (...).” (MILL, Ensaio, p. 301, CWIV, p. 322).

O método a priori - ou o método de "(...) raciocínio a partir de uma hipótese assumida (...).” (MILL, Ensaio, p. 303, CW IV, p. 325 ) - seria, então, o meio adequado de se chegar às verdades neste campo do conhecimento. E a 'hipótese assumida', no caso da economia política, seria a hipótese do homem econômico.

Por conta desta visão sobre o método correto de se chegar às verdades no campo das ciências morais, e não por ter uma visão 'empobrecida' das motivações humanas, é que Mill utiliza o homem econômico - colocando na base da ciência da economia política a motivação humana desejo por riqueza. ${ }^{9}$ Tomando esta motivação como causa, a ciência irá raciocinar dedutivamente de forma a chegar às suas conclusões.

Assim, a economia abstrairia todos os demais traços de caráter do homem e investigaria os resultados que decorreriam da ação humana “(...) sob a suposição de que o homem é um ser que é determinado, pela necessidade de sua natureza, a preferir uma maior porção de riqueza ao invés de uma menor (...).”(MILL, Ensaio, p. 301, CWIV, p. 322).

Apesar de serem decorrências da ação de inúmeras causas, os fenômenos a serem estudados pela ciência econômica teriam na motivação humana 'busca por riqueza' a sua principal causa:

$$
\begin{aligned}
& \text { "(...) A maneira pela qual ele [a economia política] neces- } \\
& \text { sariamente procede é aquele de tratar o principal fim reco- } \\
& \text { nhecido como se fosse o único fim; que, de todas as hipóteses }
\end{aligned}
$$

9 Como afirma Persky: "A mensagem a ser derivada do bomo economicus de Mill não é que os humanos são gananciosos, nem tampouco que são racionais, mas que a ciência social funciona melhor quando limita o seu escopo de forma implacável (...)." (PERSKY, 1995, p. 230). Ou ainda: "O esforço de Mill em limitar o raciocinio econômico a um conjunto de motivaçôes humanas ao mesmo tempo significantes e manejáveis era essencial a sua metodologia." (PERSKY, 1995, p. 230). Mill é explícito quando afirma: "Não porque todo economista seja sempre tão ridiculo a ponto de supor que a humanidade realmente assim se constitui, mas porque este é o modo pelo qual a ciência deve que necessariamente proceder (...).” (MILL, Ensaio, p. 301, CWIV, p. 322). 
igualmente simples, é o mais próximo da verdade. O economista político investiga quais são as ações que seriam produzidas por esse desejo se, no interior dos departamentos em questão, não fosse impedido qualquer outro desejo. Deste modo é obtida uma melhor aproximação à ordem real dos afazeres naqueles departamentos do que seria de outro modo exeqüivel."(MILL, Ensaio, p. 301, CWIV, p. 323, ênfase adicionada).

Este modo de proceder certamente coloca alguns problemas para ciência da economia, principalmente no que se refere ao status de suas conclusões vis-à-vis às ocorrências concretas.

Se os fenômenos econômicos dependem de várias causas, e somente um pequeno conjunto delas é considerado, a ciência econômica não pode ter a pretensão de prever ou explicar integralmente o que ocorre uma vez que desconsidera parte das motivações humanas que contribuem para o resultado. No entanto, para Mill, se a hipótese adotada “(...) não diferisse da verdade de nenbum modo além daquele pelo qual uma parte difere do todo, então as conclusões que são corretamente deduzidas da assunção [hipótese] constituem a verdade abstrata (...).” (MILL, Ensaio, p. 307, CW IV, p. 329).

Assim, as conclusões obtidas pela ciência econômica seriam verdades abstratas. Elas seriam verdades por serem deduzidas a partir de premissas verdadeiras conhecidas por meio de introspecção. ${ }^{10} \mathrm{E}$ seriam abstratas, pois não se deveria esperar uma correspondência perfeita entre elas e os fatos.

10 Sendo as premissas verdadeiras, a dedução - quando logicamente válida - tem o poder de transferir esse valor de verdade para as conclusóes. (CHALMERS, 1999, p. 29). E, para Mill, pelo menos em sua época, a hipótese de que a riqueza não só era uma motivação importante, como era a mais importante na esfera dos fenômenos industriais, podia ser facilmente comprovada pela introspecção e pela observação casual dos outros. Existe uma enorme polêmica na literatura sobre se Mill considerava essa motivação inerente ao homem (DE MARCHI, 2000, HIRSCH, 2000, PRADO, 1991) ou uma decorrência do ambiente institucional prevalecente no século XIX. (HOLLANDER, 1985, HOLLANDER \& PEART, 2001, MATTOS, 1997 e 1999a). No entanto, uma coisa ninguém questiona: a crença de Mill na predominância desta motivação em sua época e país. 
Desta forma, Mill não tem a menor preocupação em colocar a teoria à prova por meio de uma comparação entre as suas previsões e os fatos. ${ }^{11} \mathrm{~A}$ nãoconcordância com os fatos é, dado o tipo de método adotado, antecipada e esperada. Só se deveria esperar previsão perfeita caso apenas aquelas motivações e eventos considerados pela teoria estivessem em ação. Ou seja, estas verdades abstratas só seriam condizentes com a realidade se a definição 'arbitrária' de homem adotada pela ciência econômica fosse uma representação completa do homem de 'carne e osso' - o que, de antemão, sabe-se não ser. Nas palavras de Mill, as conclusões da ciência da economia política:

\section{"(...) seriam verdadeiras sem qualificação apenas num caso que} seja puramente imaginário. À medida que os fatos reais se afastam da hipótese, ele [o economista político] deve admitir um desvio correspondente da estrita letra de sua conclusão; de outro modo, ela [a conclusão] será verdadeira somente para aquelas coisas que ele arbitrariamente supôs, não para aquelas que realmente existem. (Mill, Ensaio, p. 304/5, CW IV, p. 326).

Assim, dentro da concepção milliana “(...) nunca testamos a validade de teorias, pois as conclusões são verdadeiras como um aspecto do comportamento humano, graças às suposições, as quais, por sua vez, são verdadeiras por estarem baseadas em fatos evidentes da experiência humana."(BLAUG, 1993, p. 115). A idéia de utilizar os fatos para testar a veracidade ou falsidade da ciência é algo que, em Mill, não faz o menor sentido. ${ }^{12}$ Como afirmou Hirsch:

11 Sobre isso Blaug afirma: "Mill, juntamente com todos os escritores da tradição clássica, recorria fundamentalmente a suposiçôes [ou premissas] ao julgar a validade [da teoria], enquanto os economistas modernos, como veremos, recorrem basicamente a previsões (...)." (BLAUG, 1993, p. 114). Não concordo com a generalização feita por Blaug. Existem vários autores modernos que refutam o falsificacionismo e o instrumentalismo - entre eles Hausman (1992), que se inspira fortemente em Mill, e autores ligados à corrente de retórica - que não adotam e questionam esse procedimento.

12 Tendo com ponto de partida a metodologia popperiana, Blaug mostra-se crítico em relação à metodologia de Mill. Ele o acusa de não estar disposto a permitir que a sua teoria seja falseada. (BLAUG, 1993, p. 104). Afirma, ainda, que diante de fatos que evidentemente contrariavam a teoria ricardiana e malthusiana Mill não fez a menor menção de abandoná-las. Ao contrário, ao longo de todas as edições dos PPE, ele teria continuado a adotar essas duas teorias, justificandoas por meio de estratagemas imunizadores. (BLAUG, 1993, p. 112). Apesar de discordar de Blaug em outros aspectos, de Marchi concorda parcialmente com ele ao afirmar: "(...) testar, de fato, hipóteses, está além de Mill. Blang está certo quando ele caracteriza a metodologia de Mill como implicando que discrepâncias entre o que se antecipou e os fatos não revelam que a afirmação original está errada, mas apenas que é insuficiente." (DE MARCHI, 1988, p. 152). Para uma avaliação da aderência empírica da teoria ricardiana ver DE MARCHI (1970). 
"Dada essa concepção de ciência econômica, uma razão pela qual a verificação não pode assumir o papel em geral atribuido a ela - ou seja, testar a teoria ao determinar se suas implicações estão de acordo com aquilo que realmente ocorre - fica evidente imediatamente. Se é conhecido que as implicações da ciência econômica não irão em geral estar de acordo com o que realmente ocorre porque raciocinamos unicamente com base nessas três leis comportamentais, então que necessidade temos de verificar a teoria abstrata ou ciência econômica que é fundamentada somente nessas três leis causais? O que se tem a aprender com a verificação que sabemos - por termos montado as coisas desta forma - mostrará somente as limitaçôes das prediçôes da teoria?” (HIRSCH, 1992, p. 847).

Para Mill, o cientista não precisa se preocupar com essa questão de confrontar os resultados da ciência com os fatos. Ele é muito claro ao afirmar que (...) $o$ exame da concordância, em qualquer caso real, dos fatos à hipótese, não constitui de modo algum uma parte da tarefa da ciência, mas da aplicação da ciência.” (MILL, Ensaio, p. 303/4, CW IV, p. 325).

Chegar às verdades abstratas (como todas as suas 'limitações em termos de predições') seria a única função do economista político enquanto cientista. ${ }^{13}$ Neste ponto terminaria a tarefa da ciência. No entanto, isso não implica dizer que Mill não tinha preocupação com a relação entre teoria e realidade, mas somente que a análise dessa questão cairia fora do escopo da ciência.

13 Descrevendo a ciência da economia política de Mill, Hirsch afirma: “(...) consiste em um corpo de teoria que deduz implicaçôes verdadeiras a partir de leis causais verdadeiras, sem qualquer consideração sobre se as implicaçôes estão de acordo com os fatos da experiência (....).” (HIRSCH, 1992, p. 845) 


\section{A CIENCLA E SUA APLICAÇÃO: CONSTRUINDO A PONTE ENTRE AS 'VERDADES ABSTRATAS' E 'CONCRETAS' ${ }^{14}$}

A afirmação de que a verificação não é assunto da ciência não deve ser tomada como indício de menosprezo pelas evidências empíricas. Seria errôneo concluir, a partir do tratamento dedutivo dado à ciência da economia política, que Mill era um adepto do que hoje se denomina "armchair economics" e que pouco se preocupava com os 'fatos' - deixando para terceiros a tarefa (menor) de aplicar os princípios abstratos da ciência. Muito pelo contrário, como foi mencionado, grande parte de sua vida e de seu esforço intelectual foi justamente no sentido de intervir visando modificar a sua realidade, e os princípios científicos eram vistos como instrumentos as serem usados a serviço desse fim.

A questão de como se relacionam as verdades abstratas da ciência e os fenômenos concretos era importante e foi abordada do ponto de vista metodológico ao final do Ensaio quando Mill trata da aplicação da ciência. ${ }^{15}$

Como vimos, as verdades abstratas seriam 'verdades' por serem deduzidas a partir de uma hipótese que, apesar de não descrever de forma completa as motivaçóes humanas, descreveria uma parte (a mais relevante para o fenômeno em questão) destas motivações. Elas representariam apenas uma parcela e não a totalidade do fenômeno econômico:

14 Um dos pareceristas da revista observou, corretamente, que Mill utiliza a expressão 'verdades no concreto'(truth in the concrete) e não 'verdade concreta' (concrete truth). No entanto, optei por falar em 'verdades concretas' por considerar que essa forma é mais direta e, no meu entender, reflete bem a idéia de Mill. Deve-se, no entanto, como ressaltou este parecerista, tomar cuidado para não interpretar a expressão 'verdade concreta' como se referindo à oposição entre o que é real e o que é aparente - categorias que não fazem sentido dentro da filosofia do autor.

15 Aqui estou seguindo a leitura que HIRSCH (1992, p. 844/5 e 2000, p. 352/3) faz do Ensaio como sendo estruturado da seguinte forma: A primeira parte trataria de definição, a segunda trataria da ciência da economia em si (ou economia abstrata), e a terceira lidaria com a aplicação da ciência. Entretanto, essa interpretação não é consensual. HOLLANDER \& PEART (2000), por exemplo, em sua análise do Ensaio utilizam trechos do final do texto (que na leitura de Hirsch diriam respeito unicamente à aplicação da ciência) ao discorrerem sobre o papel que a experiência teria na elaboração da ciência econômica. 
“(...) Na medida em que se sabe, ou se pode presumir que a humanidade na procura da riqueza está sob a influência colateral de algumas outras propriedades de nossa natureza (...) as conclusões da economia politica falharão nessa medida em serem aplicáveis à explicação ou previsão dos eventos reais até que sejam modificadas pela admissão correta do gran de influência exercido pelas outras causas.” (MILL, Ensaio, p. 302, CWIV, p. 323).

Assim, para se chegar a verdades concretas seria necessário acrescentar às causas consideradas pela ciência da economia política as demais causas que, apesar de menos relevantes, influenciam a ação humana em cada situação específica. Ou seja, seria necessário complementar as hipóteses comportamentais associadas ao homem econômico de forma a que ele se torne mais parecido com o homem de 'carne e osso' - que é quem age no mundo social. Nas palavras de Mill: "Esta aproximação [fornecida pela ciência da economia política] deve, portanto, ser corrigida, fazendo-se concessão apropriada aos efeitos de alguns impulsos de uma descrição desigual que se pode mostrar que interferem no resultado de qualquer caso particular (...)" (MILL, Ensaio, p. $301 / 2, C W I V$, p. 323 , ênfase adicionada). ${ }^{16}$

A ciência da economia política (à semelhança das outras ciências) só incorpora aquelas causas que atuam em todos os casos. No entanto, pode acontecer que em casos específicos outras causas sejam tão importantes para a determinação do resultado quanto aquelas consideradas pela ciência. No momento da aplicação prática seria necessário incorporar, aos resultados da ciência, os impactos dessas outras causas - 'perturbadoras' -, aproximando-se, desta forma, de uma descrição completa do fenômeno. Ou seja, o sistema teórico a ser utilizado para fazer previsóes concretas precisaria ser expandido de forma a levar em conta inúmeros fatores abstraídos propositadamente pela ciência econômica.

16 O parecerista antes referido também sugeriu uma tradução alternativa para o final desta passagem na qual "efeitos de alguns impulsos de uma descrição desigual' seria substituída por 'efeitos de quaisquer impulsos de outro tipo." 
Um passo fundamental nesse processo de tornar a ciência 'aplicável' seria conhecer a distância existente, no caso em questão, entre a abstração utilizada pela ciência e o homem 'real'. Ou seja, conhecer em que medida as motivações humanas ignoradas pela ciência influenciam a ação nesse campo de fenômenos para poder, posteriormente, incorporá-las à análise.

No Ensaio, Mill afirma que o estudo dessas outras motivações seria pertinente ao campo que ele denomina Economia Social. No entanto, ele não se preocupa em definir essa ciência ou em atribuir-lhe um método de investigação específico. Assim, se nos restringirmos a esse texto, ficamos com poucas pistas sobre como as informações sobre essas motivações humanas seriam obtidas e utilizadas na 'correção' das verdades abstratas da economia. No entanto, no livro VI da Lógica, ${ }^{17}$ Mill nos apresenta uma ciência que teria como o seu objeto o estudo do caráter humano em uma época e país e seus determinantes, ou seja, que lidaria com a integridade das motivações humanas, e a ela denomina etologia política.

Ao lidar com o homem em todas as suas dimensões, esta ciência poderia indicar quais seriam os 'impulsos de outro tipo' ou as 'leis comportamentais' a serem adicionadas na hora da aplicação dos princípios abstratos da ciência às situações específicas.

Resta definir melhor a ciência da etologia política e discutir como ela poderia ajudar aquele que busca aplicar os conhecimentos científicos da economia aos problemas que o mundo real coloca.

\section{II.1 A Etologia Política: 'Humanizando' o Homem Econômico}

Mill acreditava que o homem era, em um sentido bastante forte, fruto do meio em que vivia. Para ele, o caráter humano seria resultado da interação

17 Como já mencionado, na passagem do Ensaio para a Lógica pouca coisa mudou em termos de metodologia da economia, mas sua visão das demais ciências sociais e de suas inter-relações alterouse bastante sob a influência de Comte, Coleridge e outros. Para um tratamento mais detalhado dessas mudanças ver WHITAKER (1975), MATTOS (1999b), LEWISOHN (1972). 
entre algumas leis básicas da mente humana e as circunstâncias às quais o indivíduo é exposto. Dadas essas leis psicológicas, o caráter tenderia a ser diferente à medida que as circunstâncias diferissem - isso explicaria a enorme diversidade de tipos de caráter existente. ${ }^{18}$

A etologia seria a ciência que versaria sobre as leis de formação de caráter, ou seja, determinaria o tipo de caráter a ser produzido - em conformidade com as leis da mente - por qualquer conjunto dado de circunstâncias físicas e morais. (MILL, Lógica, p. 54). Esta ciência era de grande relevância para Mill por ser o elo entre os princípios da psicologia e as generalizações empíricas existentes sobre o caráter humano. Ela daria um caráter científico a essas generalizações ao ligá-las aos princípios básicos da natureza humana.

Mas, para os fins desse artigo, é o ramo aplicado desta ciência 'mãe' - a etologia política - que tem maior interesse. A etologia política seria “(...) a teoria das causas que determinam o tipo de caráter pertencente a um povo ou a uma época.” (MILL, Lógica, p. 93). ${ }^{19}$

Para Mill, as circunstâncias gerais às quais todos os indivíduos são expostos (tipos de instituições sociais vigentes como, por exemplo, o sistema de educação, as crenças religiosas, o tipo de relações econômicas que prevalecem, os costumes etc.) teriam um peso preponderante no caráter resultante. Isso permitiria a identificação de traços de caráter característicos de uma região ou país, ou seja, de um caráter nacional ou coletivo. Assim, com base nas leis de formação de caráter e em informações sobre as principais instituições

18 Como afirma Ryan, Mill estava “(...) ansioso em concordar que é possível que existam poucas faculdades (capacities) humanas básicas, e que as circunstâncias podem dar conta de quase toda a diversidade que observamos (...)."(RYAN, 1990, p. 161/2). Para uma análise mais completa de quais seriam as leis da mente, do papel das circunstâncias na formação do caráter e das implicações desta visão, ver MATTOS (1998), AYER (1987). É importante notar, como ressaltou um dos pareceristas anônimos da revista, que Mill não foi o primeiro nem o único autor a pensar sobre o caráter humano e a tentar articular essas preocupações com a economia política.

19 Em MATTOS (1999) a importância da etologia na hierarquia de ciências de Mill é ressaltada. Ela seria, entre outras coisas, determinante na indicação de quais ramos das ciências morais poderiam ser investigados de forma autônoma pelo método dedutivo e quais deveriam submergir na Grande Ciência Social e ser investigados pelo método dedutivo inverso (ou histórico). 
sociais vigentes em dado local e momento do tempo, a etologia política indicaria o tipo de caráter nacional que tenderia a prevalecer. ${ }^{20}$

Vimos anteriormente que Mill acreditava na utilidade de usar a abstração homem econômico e que as demais motivações do homem não deveriam ser incluídas no campo da ciência, mas consideradas causas perturbadoras a serem levadas em conta somente no momento de se fazer alguma previsão sobre eventos econômicos futuros ou de explicar ocorrências passadas. E neste contexto de aplicação da ciência à prática, as considerações etológicas serviriam de complemento para as verdades abstratas da economia.

Ryan vai bem ao ponto quando afirma que Mill "(...) tenciona indicar que, apesar de a economia ser apenas uma contribuição para um entendimento mais completo da sociedade, de qualquer forma irá servir como uma contribuição. Suas conclusões não podem ser aplicadas diretamente à predição do que irá acontecer na sociedade, mas servem como uma aproximação a ser corrigida. Assim, no Sistema de Lógica, Mill chama a etologia politica em seu auxilio (...).” (RYAN, 1990, p. 143).

A etologia política auxiliaria a economia ao dar uma medida do grau de adequação das hipóteses a respeito de desejos e motivaçôes das quais parte essa ciência. Ao fornecer valiosas informações sobre as motivações humanas (além do desejo de riqueza) que estariam determinando a ação do homem na esfera econômica, ela desempenharia um papel importante na tarefa ora analisada de transformar verdades abstratas em verdades concretas passíveis de serem utilizadas para a compreensão e previsão dos fatos econômicos.

20 A etologia e a etologia política eram fundamentais para o projeto de Mill enquanto reformador social. Elas poderiam servir de guia para aqueles que quisessem moldar o caráter dos homens, ao indicar quais seriam as instituições mais adequadas para produzir os efeitos desejados. " $O$ assunto a ser estudado é a origem ou a fonte de todas as qualidades nos seres humanos que são interessantes para a gente como fatos a serem produzidos, evitados ou meramente entendidos; e o objetivo é determinar, a partir das leis da mente combinadas com a posição geral da nossa espécie no universo, quais combinações existentes ou possíveis são capazes de promover ou evitar essas qualidade.” (MILL, Lógica, p. 59). Para uma análise mais cuidadosa da Etologia, ver PERSKY (1995), LEARY (1983), MATTOS (1998), FEUER (1976). 
"(...) a etologia informa-nos sobre quão plausíveis são as suposições a respeito das necessidades e desejos das quais a economia parte e pode, por isto, nos dar alguma idéia sobre onde as nossas expectativas provavelmente não serão preenchidas." (RYAN, 1990, p. 157).

Essa correção utilizando informações etológicas fazia-se necessária, segundo Mill, mesmo nos casos da Inglaterra e dos EUA - países nos quais havia uma forte predominância das motivações consideradas pela ciência da economia política. Ela tornava-se ainda mais importante em países (ou regiões) nos quais a motivação busca por riqueza era significativamente mais fraca. E Mill criticava a falta de clareza dos seus colegas de profissão sobre esse ponto.

"O economista politico inglês, tal como os seus compatriotas, raramente tem consciência de que é possível que homens, conduzindo seu comércio de vender suas mercadorias sobre um balcão, podem estar mais preocupados com o seu sossego e vaidade do que com seu ganbo pecuniário. No entanto, aqueles que conbecem os hábitos da Europa Continental estão cientes de como esses motivos aparentemente menores, freqüentemente preponderam sobre o desejo de ganbar dinbeiro, mesmo em operações que têm ganhar dinbeiro como seu objetivo ..." (MILL, Lógica, p. 94, ênfase adicionada). ${ }^{21}$

Nesse caso, os resultados antecipados pela ciência afastar-se-iam de forma considerável dos fenômenos concretos, e precisariam ser largamente 'corrigidos' de modo a engendrar explicações e previsões satisfatórias e a cumprir a sua função de dar subsídios para os homens públicos tomarem suas decisões.

21 Em MATTOS (1999a) argumenta-se que, no caso de a motivação busca de riqueza ser menos importante que outras motivações humanas, a economia política não cumpriria os quesitos necessários para ter status de ciência autônoma e deveria ser estudada junto com os demais fenômenos sociais pelo método dedutivo inverso (ou histórico). 
Por conta da relevância de se fazer essas e outras correções antes de tentar aplicar os princípios da ciência, Mill afirma que "(...) o simples economista político, aquele que não estudou nenbuma ciência a não ser a economia política, se tentasse aplicar a sua ciência à prática, fracassaria." (MILL, Ensaio, p. 308, CWIV, p. 331).

\section{II.2 A Importância do Conbecimento 'Não Cientifico'}

Até agora ênfase foi dada ao papel desempenhado pela etologia política na 'humanização' do homem econômico.

Existem fatores que são determinantes em uma dada situação, mas que não são universais o suficiente na determinação dos resultados econômicos para serem considerados pela ciência da economia política, sendo tratados como 'causas perturbadoras' a serem incorporadas apenas no momento da aplicação. Vimos que as motivações humanas de descrição diferente daquelas associadas ao homem econômico seriam talvez as principais 'causas perturbadoras'. Mas, apesar de consideradas 'perturbadoras' pela economia, se puderem ser associadas às leis de formação de caráter, serão parte das verdades da ciência da etologia política. ${ }^{22}$ Assim, a relação entre a etologia política e economia política é uma relação entre duas ciências dedutivas, uma fornecendo informações que complementariam o resultado da outra.

Mas existem outras causas que podem ter muita relevância em um caso específico, mas que não têm universalidade o suficiente para fazer parte de qualquer ciência (seja ela a economia ou a etologia) e nem por isso deixam de ser fundamentais na produção dos resultados..$^{23}$

22 Por exemplo, em uma situação específica o nacionalismo pode ser muito relevante para a determinação do resultado econômico, mas pelo fato de sua relevância não ser universal o suficiente não será considerado pela ciência da economia política. No entanto, se for possível mostrar que, dadas as leis psicológicas, as instituiçốes vigentes tenderiam a engendrar esse tipo de motivação, o sentimento nacionalista, será parte das verdades da ciência da etologia política.

23 "Quando os princípios da economia politica devem ser aplicados a um caso particular, é necessário, então levar em conta todas as circunstâncias individuais daquele caso, não apenas examinando a qual dos conjuntos de circunstâncias contemplados pela ciência abstrata as circunstâncias do caso em questão correspondem, mas de modo análogo que outras circunstâncias podem existir naquele caso que não sendo comuns a ele com qualquer classe ampla e fortemente marcada de casos, náo caíram sob a cognição da ciência.” (MILL, Ensaio, p. 307, CWIV, p. 330, ênfase adicionada). 
Assim, a discussão metodológica que está sendo feita sobre a aplicação dos princípios científicos para explicar/prever (e, eventualmente, manipular) os fenômenos concretos fica incompleta se não levarmos em consideração um outro tipo de informação: o conhecimento das particularidades da situação em questão. Essas informações seriam obtidas pelo método a posteriori - a observação direta dos fenômenos em toda a sua complexidade - que vimos ser impróprio para a ciência, mas que seria, para Mill, de grande valia no momento da sua aplicação, ao apontar elementos específicos ao caso em questão, cuja ausência no sistema poderia levar a previsões pouco precisas.

E esse conhecimento é fornecido pela vivência daqueles que têm ampla experiência da situação, apesar de muitas vezes não serem versados nas ciências. Essas informações incluem desde generalizações empíricas - que não têm qualquer status científico por não serem vinculadas às causas (podendo ser meras correlações) - até o conhecimento de particularidades institucionais. ${ }^{24}$

Por exemplo, vai ser muito importante para quem for determinar o que se paga de renda da terra, em determinado país e época, saber que há uma lei específica (ou mesmo hábito secular) fixando a porcentagem do produto a ser pago na forma de renda. Ou para quem quiser determinar qual é a taxa de lucro a prevalecer num determinado setor é muito relevante saber que existe um monopólio estatal que impede a entrada de concorrentes.

Ou seja, mesmo que todas as 'correções' no que tange às motivações dos homens sejam incorporadas, a ausência destas informações levaria a uma distância importante entre as conclusões da teoria (já corrigida pelas considerações etológicas pertinentes) e o que se observa de fato. ${ }^{25}$

24 Poderiam até ser generalizações empíricas sobre traços de caráter da população, mas que por não estarem ligados às leis da psicologia humana não teriam um status científico.

25 “(...) Existem muito mais coisas envolvidas na 'teoria' utilizada para a aplicação do que na 'teoria' do modelo básico da ciência [da economia politica]; pode incluir elementos da sociologia e da etologia, causas menores que não são incluidas como parte do modelo básico, constantes empiricas fornecidas pelo homem prático e a combinação de alguns ou todos esses elementos (...) E é com base nessa 'teoria' que se tem confiança para levar adiante o trabalho de implementação de politicas." (HIRSCH, 2000, p. $354)$. 
Mill deixa clara a importância deste complemento quando afirma que se um político especulativo - aquele que já trabalha com uma teoria ampliada para dar conta de todas as motivações humanas - não olhar a experiência específica: "(...) deve ficar satisfeito em não tomar nenhuma parte na politica prática; em não ter nenhuma opinião ou sustentá-la com extrema modéstia, nas aplicações que devam ser feitas de suas doutrinas às circunstâncias existentes." (MILL, Ensaio, p. 310, CW IV, p. 333).

Só depois de corrigidas pelos fatores etológicos e pelas informações sobre a situação específica do caso é que faz sentido nutrir-se a expectativa de as conclusões assim derivadas aproximem-se do que realmente ocorre. Mill afirma que "(...) [a] quilo que é verdadeiro no abstrato é sempre verdadeiro em concreto, com concessóes apropriadas.” (MILL, Ensaio, p. 305, CW IV, p. 326). E estas seriam as principais 'concessões' necessárias para transformar verdades abstratas em verdades concretas. Nas palavras de Hirsch:

\begin{abstract}
“(...) é somente depois que o politico especulativo é chamado em cena para adicionar as outras leis comportamentais aos seus cálculos, e que o 'homem prático adiciona seu conbecimento intimo sobre as especificidades da situação envolvida, e que tudo isso seja agregado em uma bipótese sobre quais são as conseqüências que se espera seguir de uma proposta de politica especifica aplicada em um momento e local especifico, é que verificaçôes significativas podem ocorrer." (HIRSCH, 1992, p. 850).
\end{abstract}

\title{
II.3 A Função da Verificação
}

Como vimos, Mill deixa claro que a verificação (ou seja, o processo de comparar as conclusões da teoria e os fatos) não desempenha nenhum papel na ciência da economia política, no entanto, ela teria uma função importante no momento de aplicar seus princípios.

A comparação das conclusões da teoria (ampliada e corrigida pelos fatores acima citados) com fatos da experiência é um momento fundamental: 


\begin{abstract}
"Se, por exemplo, nós quiséssemos aplicar nossas especulações sobre economia política para a predição ou como guia para os fenômenos de qualquer país, teriamos que ser capazes de explicar todos os fatos industriais ou mercantis de caráter geval pertencentes ao estado presente daquele pais: de apontar as causas que são suficientes para dar conta de todos eles, e provar ou mostrar que existem boas razões para acreditarmos que essas causas realmente existiram (...).” (MILL, Lógica, p. 99).
\end{abstract}

É da capacidade de dar conta dos fenômenos passados ou presentes que derivaríamos a confiança na sua capacidade de dar conta do futuro. Como afirma Mill:

\title{
"O teste do grau no qual a ciência fornece base segura para a predição e, consequentemente, para lidar praticamente com o que não aconteceu ainda, é o grau no qual ela nos permitiu prever o que de fato ocorreu." (MILL, Lógica, p. 99).
}

A inexistência de concordância entre a observação empírica e as conclusões teóricas aponta que há falhas, seja nos elementos selecionados para serem incorporados como 'causas perturbadoras', seja no próprio âmbito da teoria. ${ }^{26}$ Se existe qualquer resíduo ainda não explicado, deve-se procurar localizar onde está a deficiência. ${ }^{27}$ Ou seja, “(...) temos que procurar entre as circuns-

26 "(...) Se nãa pudermos fazer isso, é uma prova de que ou não conbecemos completamente os fatos que deveriam ser considerados, ou que, apesar de os conbecermos, não temos dominio de uma teoria suficientemente perfeita para nos possibilitar determinar as suas conseqüências. Em qualquer um dos casos não estamos, no estado presente do conbecimento, completamente qualificados para tirar conclusóes, sejam elas especulativas ou práticas (...).” (MILL, Lógica, p. 99).

27 PEART (1995) afirma que ao dar ênfase às causas perturbadoras no momento da aplicação da ciência Mill ergueu um obstáculo para a utilização de procedimentos estatísticos entre os economistas, pois ele propunha tratar cada caso como um 'estudo de caso' no qual não caberia o uso de grandes médias e combinações de resultados. (p. 1195). A autora contrasta essa posição com a de Jevons, que segundo ela: "(...)recomendou o que equivalia a uma abstração das cansas perturbadoras também na aplicação. Na prática, os cientistas sociais deveriam assegurar-se de que as 'causas perturbadoras' se 'equilibram' ('balance'); somente fracassando isso é que o cientista poderia fazer ajustes de forma a considerar essas 'causas perturbadoras'. Assim, a metodologia de Jevons na prática ou na aplicação de fato minimizava a importáncia das 'causas perturbadoras', que não precisavam mais ser explicadas ou consideradas, podendo, ao contrário, ser ignoradas (...)” (PEART, 1995, p. 1195). E conclui que Jevons "(...) removeu um obstáculo importante ao desenvolvimento e à apropriação de métodos estatísticos na economia.” (idem). 
tâncias do caso particular até encontrar uma que, dados os princípios da teoria existente, dê conta do fenômeno não explicado, ou temos que voltar, e procurar pela explicação através de expansão e melhoramento da própria teoria." (MILL, Lógica, p. 99).

Poderia parecer que esta passagem contradiz a afirmação feita por Mill de que a verificação não desempenha qualquer papel no campo da ciência da economia política. Hirsch aponta, entretanto, que se deve interpretar a 'teoria' a qual Mill está se referindo como sendo aquele sistema mais amplo (que já incorpora as correções julgadas necessárias dados os conhecimento da etologia política e das especificidades do caso particular) utilizados no momento da aplicação da ciência. ${ }^{28}$

"... Mill acreditava, como foi dito, que para ser capaz de prever énecessário levar em conta outras leis psicológicas além das consideradas na economia, ou colocado de outra forma, a ciência abstrata a ser usada na aplicação é a da política especulativa (...) Assim, quando no contexto de aplicação retroativa (retrodictive aplication) o político especulativo (ou o economista político atuando nessa função), que mesmo conbecendo os fatos percebe-se incapaz de determinar quais seriam os seus efeitos, $e$ conclui que mudanças no 'sistema abstrato' precisam ser feitas, o sistema abstrato é aquele da política especulativa (...) $\mathrm{Na}$ medida em que as deficiências se derivam da ciência, pareceria, então, que as inadequações no sistema mais abrangente da

28 Essa interpretação não é consensual na literatura secundária sobre Mill e foi o ponto central do debate acima citado que ocorreu recentemente sobre a metodologia de Mill. O debate que teve como protagonistas iniciais HOLLANDER (1985) e HIRSCH (1992), mais recentemente foi retomado com os artigos de HOLLANDER \& PEART (1999), a réplica de HIRSCH (2000) e a tréplica de HOLLANDER \& PEART (2000) no Journal of the History of Economic Thought (JHET). HOLLANDER (1985) e HOLLANDER \& PEART (1999 e 2000) interpretam o termo 'teoria' como sendo teoria (ou ciência) econômica. Eles entendem, assim, a citação como sendo um indício de que a experiência específica teria um papel importante a cumprir na ciência da economia política, ao levar a reformulações teóricas. Hirsch, como acabamos de ver, defende, por sua vez, que Mill está se referindo ao modelo já expandido utilizado na aplicação, e não à ciência da economia política. Como deve estar claro no texto, considero a posição de Hirsch mais convincente, e adoto interpretação similar. 


\section{politica especulativa estariam de forma geral causando}

o fracasso da explicação retroativa (retrodictive failure)."

(HIRSCH, 1992, p. 859, ênfase adicionada). ${ }^{29}$

Assim, o processo de verificação teria a importante função de orientar aquele que visa aplicar a teoria, para a necessidade de inserção de elementos específicos àquela situação (informação fornecida pelo 'homem prático') ou de modificação de elementos da própria teoria (ou seja, reconsideração de fatores que estariam afetando as motivaçóes humanas). Somente quando o fenômeno fosse totalmente explicado é que seria possível confiar nesse conhecimento para fins de aplicação e como guia de ação.

\section{CONCLUSÃO}

A forma como Mill caracteriza o empreendimento científico e lida metodologicamente com a questão da relação entre a ciência econômica (necessariamente abstrata e unidimensional) e a realidade que se pretende explicar sem dúvida coloca questões relevantes. Até hoje a economia é concebida como uma ciência dedutiva e, sem dúvida, a maior parte dos modelos econômicos engendra resultados bastante abstratos e que demandam algum tipo de qualificação para que dêem conta de explicar, na sua integridade, a esfera dos assuntos econômicos e para que sejam guias razoáveis para a intervenção no mundo social. No entanto, depois de toda essa empreitada metodológica, parece-me que o caminho pavimentado é insuficiente para guiar aquele que deseja fazer essa importante ponte entre teoria e realidade.

Acredito que uma das dificuldades está no fato de que, apesar de ser uma peça fundamental na aplicação dos princípios econômicos (e das demais ciências sociais), a etologia política pouco se desenvolveu como ramo do

29 É necessário lembrar que no Ensaio 1836 a hierarquia das ciências morais ainda não estava completa e Mill usa o termo Política Especulativa para se referir à ciência que abarcaria as demais motivações humanas. Na Lógica, essa ciência não aparece mais e a ciência que vai assumir essa função de complementar a economia política é a etologia política. 
saber. O próprio Mill aponta essa ciência como sendo o ramo da ciência social que se encontra “...mais completamente em sua infáncia (...)” (MILL, Lógica, p. 93), o que não surpreendia dado "(...) o estado infante (infant state) da própria ciência da etologia, de onde as leis têm que ser derivadas, e das quais as verdades da etologia politica não podem ser senão resultados e aplicações (...).” (MILL, Lógica, p. 94).

Assim, a etologia política, apesar de ser apontada no discurso de Mill sobre a ciência como crucial, nunca pôde desempenhar a contento as funções a ela atribuídas. Mill estava ciente desse fato e considerava que “(...) a parte mais imperfeita daqueles ramos da investigação social que foram cultivados como ciências separadas [como, por exemplo, a economia política] é a teoria da forma pela qual as suas conclusões são afetadas por considerações etológicas (...).” (MILL, Lógica, p. 94/5). Esse fato, apesar de não as comprometer como enquanto ciências abstratas, “(...) as vicia nas suas aplicações (...).” (MILL, Lógica, p. 94).

Provavelmente Mill nutria esperanças no avanço e desenvolvimento dessa ciência. Ele próprio empreendeu uma tentativa de escrever um livro sobre etologia entre 1843 e 1845. No entanto, ele acabou por desistir do projeto e voltou-se para escrever os Princípios de economia politica. (WHITAKER,1975, p. 1036). ${ }^{30}$ Outros tampouco o fizeram nos moldes concebidos por Mill. ${ }^{31}$ Assim, ficamos sem ter como tornar operacional a idéia de utilizar a etologia para 'corrigir' os resultados da economia.

Não está sendo sugerido aqui que a idéia de etologia não influenciou a forma como Mill fez de fato economia. Apesar de ter fracassado na tentativa de

30 Mill reconhece esse 'fracasso' ao dizer em correspondência a Bain: “(...) Eu não sei quando estarei maduro para começar a 'Etologia'. O projeto ainda não assumin qualquer formato definitivo para mim ainda." (MILL, apud LEARY, 1982, p. 154).

31 Analisando as razões do fracasso do projeto de construir a etologia, Leary o atribui a basicamente dois fatores: em primeiro lugar, a psicologia associacionista (que estava na base da etologia) já estava totalmente se tornando obsoleta e explicações mais biológicas ganhavam força na época; e, além disso, o método eleito por Mill para desenvolvê-la (dedutivo) seria muito difícil de ser aplicado. (LEARY, 1982, p. 155). 
construir uma etologia ele nunca deixou de considerá-la essencial e de estar atento à multiplicidade de caracteres nacionais e a seus impactos.

Os Princípios não diziam respeito somente aos princípios abstratos da ciência econômica: esses princípios eram apresentados juntamente com as suas aplicaçóes. Basta lembrar que o título completo de sua principal obra econômica é Princípios de economia politica: com algumas de suas aplicações à filosofia social.

Ao descrever seu livro para Henry Chapman, Mill fez questão de frisar esse ponto: "(...) ao mesmo tempo que incorpora toda a ciência abstrata no estado mais completo já atingido [os Princípios visavam a ser] essencialmente um livro de aplicaçôes exibindo os princípios da ciência no concreto."(MILL, 1963, p. 708-9, apud WHITAKER, 1975, p. 1047, ênfase adicionada)..$^{32}$

Assim, com ou sem uma ciência da etologia política disponível para guiar a tarefa de 'correção' das verdades abstratas, Mill não só pretendeu falar sobre o que ocorria em seu mundo - ou seja, fez a ponte entre o abstrato e o concreto - como adiantou muitos conselhos sobre como o Estado e a sociedade civil deveriam conduzir os assuntos econômicos.

Ele foi a todos os momentos sensível às especificidades locais e os Princípios lograram, no meu entender, êxito em utilizar os princípios da ciência para discutir questões bastante concretas de sua época e permitiram a Mill exercer um papel não só de cientista, mas de um reformador social que soube

32 Sua intenção era apresentar o 'estado das artes' da ciência econômica, e abordar (utilizando esse conhecimento) os temas de filosofia social que se faziam prementes no século XIX. O arcabouço teórico utilizado foi a teoria ricardiana, e entre os temas de filosofia social tratados nos Princípios podemos citar a questão do socialismo (alternativas ao sistema de propriedade privada); de formas de propriedade da terra; das leis de herança e de contratos; da Lei dos Pobres; dos sindicatos; do sistema educacional; das cooperativas; da pertinência de intervenção do governo em aspectos da vida econômica. À luz de tudo o que foi discutido, deve estar claro que para lidar com esses temas da época não bastava o conhecimento fornecido pela ciência da economia. 
utilizar o conhecimento fornecido pela ciência para promover os fins que ele considerava importantes para a sua sociedade..$^{33}$

O que está sendo argumentado é que a função de complementação que a etologia deveria cumprir em relação à economia não chegou a ser executada da forma como ele pregou nos seus escritos metodológicos. Mill não separou a etapa da derivação dos princípios científicos daquela de sua aplicação, e não forneceu qualquer orientação sobre como essas informações sobre as especificidades da situação e de caráter deveriam ser incorporadas à análise. ${ }^{34}$

33 É importante lembrar que Mill refletiu bastante sobre a relação entre ciência e arte. Para ele essa relação dar-se-ia em basicamente três níveis: a arte ditaria o que deveria ser buscado - ou as metas desejáveis para a sociedade; a ciência, ao explicitar as relaçốes causais existentes, revelaria as diversas alternativas que poderiam ser adotadas com vistas a obter esse resultado; dada essa informação, estamos novamente no campo da arte, no qual o homem público fará as escolhas dentre esses ou outros caminhos disponíveis. A arte certamente aprimora-se com o aprimoramento da ciência. Mas a ciência não dita fins. Como afirmou Cairnes, referindo-se à posição de Mill: "(...) Não caberia à economia política ou à qualquer ciência apontar os fins que deveriam ser buscados pelos seres humanos; a tarefa da ciência se completa quando ela nos indica os meios pelos quais este fim pode ser atingido, mas caberia a cada homem decidir o quanto este fim é desejável tendo em vista os custos envolvidos em sua obtenção. Resumindo, ele mostrou que a ciência deve estar a nosso serviço e não o inverso. Esta foi uma lição que Mill foi o primeiro a aplicar (enforce) e podemos dizer que, ao fazê-lo, ele libertou os economistas do peso (thraldom) de seus próprios ensinamentos ..." (CAIRNES, apud BAIN, 1882, p. 201). Assim, mesmo que o conhecimento a respeito de todas as causas envolvidas na produção do fenômeno fosse perfeito, ele sozinho não é suficiente para ditar a ação a ser seguida pelos homens públicos. Apesar disso, de Marchi aponta que Schumpeter acusa Mill de desrespeitar os seus próprios ensinamentos a esse respeito. Segundo Schumpeter, "(...) [Mill] tal como outros da sua época, via distinção entre a 'ciência' da economia e a 'arte' das politicas (policy), mas fez uma ligação direta entre uma e outra por meio da atribuição de competência em questôes sociais àqueles que consideravam apropriadamente os aspectos não econômicos de uma situação ao lado dos econômicos. Tal abrangência de pensamento (broad-mindeness) era julgada 'filosófica' (leia cientifica) e qualificava uma pessoa a dar conselhos. Dessa forma, a distinção categórica entre o 'é' o o 'deve ser' ficou totalmente embaçada." (DE MARCHI, 1988, p. 157). E, de fato, lendo principalmente o Ensaio, temos por vezes essa impressão.

34 É difícil saber se isso se deve à ausência de uma ciência da etologia numa forma operacional, ou se é devido a um certo afastamento de Mill em relação à própria idéia de homem econômico. Há uma certa discordância na literatura a esse respeito. Alguns autores, como MARSHALL (1982), EDGEWORTH (1896), acreditam que Mill, após ter sido exposto a inúmeras correntes de pensamento ao longo das décadas de 1830 e 1840, abandonou a idéia de homem econômico. Outros, como WHITAKER (1975), acreditam que é perfeitamente possível tornar compatível o que Mill fez nos Principios com o que ele pregou em seus artigos metodológicos. De qualquer forma, o fato é que Mill não se preocupou em primeiro chegar aos resultados abstratos da ciência, utilizando como base a abstração homem econômico, para depois aproximar as verdades assim obtidas da realidade concreta por meio da incorporação das demais informações sobre caráter ou sobre as situações específicas. 
Os Princípios foram um sucesso, conseguiram cumprir sua função, mas no meu entender Mill não conseguiu mostrar o 'caminho das pedras' de como a economia pode utilizar a abstração homem econômico - o que implica a utilização de um modelo bastante abstrato - e, ainda assim, ter coisas relevantes a dizer sobre o que ocorre no mundo e ser um bom instrumental nas mãos dos homens públicos. Mill conseguiu fazer a ponte, mas com base no seu excepcional talento, cultura e intuição. Mas, por todos os problemas acima citados, os seus escritos metodológicos são por demais genéricos para fornecer um bom guia de ação para aquele que deseja 'corrigir' as verdades da ciência da economia política. Mill indica os elementos que deveriam ser incorporados de forma a tornar os resultados da investigação econômica mais próximas àquilo que realmente ocorre, no entanto, não apresenta a forma específica de incorporá-los e nem a ponderação que se deve dar a cada um deles.

De fato, o rumo que a economia seguiu desde então foi no sentido oposto àquele sugerido por Mill. As preocupações etológicas e sociológica foram sendo paulatinamente esquecidas, não só no momento de formulação da ciência (como defendia Mill), mas também no momento de sua aplicação. Talvez pela dificuldade - que encontramos também em Mill - de encontrar uma forma rigorosa (não puramente intuitiva) de incorporar esses e outros elementos à análise.

Hoje em dia, já num outro contexto teórico, ressurge uma preocupação com o contexto institucional e como ele influencia os resultados econômicos, de um lado, e tentativas de incorporar a ética e aspectos não econômicos do comportamento humano à discussão econômica, por outro. Esperemos que essas linhas de pesquisa tenham mais sucesso do que teve Mill.

\section{REFERÊNCIAS BIBLIOGRÁFICAS}

\section{Bibliografia Primária}

MILL, John Stuart. Autobiography. London: Penguin Books, 1989. 
. Da definição de economia política e do método de investigação próprio a ela. Tradução de Pablo Mariconda, Coleção: Os Pensadores, v. XXXIV. São Paulo: Abril Cultural, 1974.

. On the definition of political economy and the method of philosophical investigation in that science. In: CWIV. Toronto: University of Toronto Press, 1967.

. Principles of political economy with some their applications to social philosophy. In: CW II e III. Toronto: University of Toronto Press, 1965.

. The logic of moral science: a repress of a system of logic. Book VI. Londres: Ducksworth, 1987.

\section{Bibliografia Secundária}

AYER A. J. Introdução ao The logic of moral science. London: Duckworth, 1987.

BAIN, A. John Stuart Mill. A criticism: with personal recollection. London: Longmans Green, 1882.

BLAUG, M. Metodologia da economia ou como os economistas explicam. São Paulo: EDUSP, 1993.

CHALMERS, A. F. O que é ciência afinal? São Paulo: Editora Brasiliense, 1999.

COLLINI, S. et alii. That noble science of politics: a study in 19th century intellectual history. Cambridge: Cambridge University Press, 1983.

DE MARCHI, N. John Stuart Mill interpretation since Schumpeter. In: W. O. (ed.), Classical political economy: a survey of recent literature. Boston: Kluwer Academic Publishers, 1988.

. Putting the evidence in it's place: John Stuart Mill's early struggles with 'the facts in the concrete. 2000. Mimeografado.

. The empirical content and longevity of Ricardian economics. Economica, v. XXXVII, n. 147, Aug. 1970.

. The success of Mill's principles. HOPE, v. 6, n. 2, 1974.

EDGEWORTH, F. John Stuart Mill. In: HIGGS, Henry (ed,), Palgrave Dictionary of Political Economy. London: Augustus M. Kelley, 1896.

FEUER, L. S. John Stuart Mill as a sociologist: the unwritten ethology. In: James and John Stuart Mill: papers of the centenary conference. Toronto: University of Toronto Press, 1976. 
FONSECA, E. G. Comportamento individual: alternativas ao homem econômico. Revista Estudos Econômicos, v. 20, n. especial, p. 5-37, 1990.

HAUSMAN, D. M. J. S. Mill's philosophy of economics. Philosophy of Science, 48, Sept. 1981.

. The inexact and separate science of economics. Cambridge: Cambridge University Press, 1992.

HIRSCH, A. John Stuart Mill on verification and the business of science. HOPE, v. 24, n. 4, 1992.

A reply to Hollander's and Peart's "John Stuart Mill's method". JHET, v. 22, n. 3, Sept. 2000.

HOLLANDER, S. The economics of John Stuart Mill. 2 volumes. Toronto: University of Toronto Press, 1985.

HOLLANDER, S.; PEART, S. John Stuart Mill's method in principle and practice: a review of the evidence. JHET, v, 21, n. 4, Dec. 1999.

A rejoinder to Abraham Hirsch. JHET, v. 22, n. 3, Sept. 2000

LEARY, D. The fate and influence of J. S. Mill's proposed science of ethology. JHI, v. XVIII, n. 3, 1982.

LEWISOHN, D. Mill and Comte on the methods of social sciences. JHI, v. 33, n. $2,1972$.

MARSHALL, A. Apendix B - The growth of economic science, Apendix C - The scope and method of economics, Apendix D - Uses of abstract reasoning in economics. In: Principles of economics. Philadelphia: Porcupine Press, 1982.

MATTOS, L. V. Economia política e mudança social - a filosofia econômica de John Stuart Mill. São Paulo: Edusp, 1998.

. A natureza humana e o 'homem econômico milliano. Revista Estudos Econômicos, v. 27, n. 1, p. 69-96, jan./abr. 1997.

A economia política como ciência autônoma - um estudo sobre as contribuições metodológicas de John Stuart Mill. Revista de Economia Politica, v. 19, n. 76, 1999a.

. John Stuart Mill, o socialismo e a sua utopia liberal: uma aplicação de sua visão de instituições sociais. Revista Estudos Econômicos, v. 29, n. 3, p. 395-4l4, jul./set. 1999 b.

MOTTA, J. F. Sobre o papel do erro no avanço do conhecimento científico e na economia política de John Stuart Mill. In: BIANCHI, A. M. (org.), Metodologia da economia: ensaios. São Paulo: IPE-USP, 1988. 
PEART, S. 'Disturbing causes', 'noxious errors', and the theory-practice distinction in the economics of J. S. Mill and W. S. Jevons. Canadian Journal of Economics, XXXVIII, n. 4b, November 1995.

PEART, S.; LEVY, D. Denying human homogeneity: eugenics \& the making of neoclassical economics. Trabalho apresentado no Encontro da History of Economics Society, junho de 2000.

PERSKY, J. Retrospectives: the ethology of homo economicus. Jornal of Economic Perspectives, v. 9, n. 2, Spring 1995.

POPPER, K. The autonomy of sociology. In: SCHNEEWIND, J. B. (ed.), Mill: a collection of critical essays. London, 1968.

PRADO, E. F. S. Economia como ciência. São Paulo: IPE-USP, 1991.

RYAN, A. The philosophy of John Stuart Mill. New Jersey: Humanities Press International Inc, 1990.

WHITAKER, J. J. S. Mill's methodology. Journal of Political Economy, v. 83, n. $5,1975$.

WINCH, D. Marginalism and the boundaries of economic science. HOPE, v. 4, n. $2,1972$.

Este artigo foi apresentado no VII Encontro Nacional de Economia Política e no XXX Encontro Nacional da ANPEC. Agradeço ao CEPE da PUC-SP pelo auxílio financeiro. Agradeço também os comentários de Ana Maria Bianchi, Maria de Lourdes Mollo, Antônio Carlos dos Santos, de Ângelo Alberto Xella, e dos dois 'pareceristas' anônimos da revista. Finalmente, gostaria de agradecer a Raul Cristóvão dos Santos que, com os seus comentários, reflexóes e 'dicas', tem ajudado a manter vivo o meu interesse por História do Pensamento Econômico.

E-mail: lauramat@uol.com.br

(Recebido em janeiro de 2003. Aceito para publicação em julho de 2003). 